\section{Pollination Timing and Hybrid Seed Production of Neoregelia}

\author{
Chyun-Chien Liang, Tzu-Yao Wei, and Der-Ming Yeh \\ Department of Horticulture and Landscape Architecture, National Taiwan \\ University, Taipei 10617, Taiwan
}

Additional index words. cross-pollination, cut style, fertilization barrier, style length, stigma receptivity

\begin{abstract}
Neoregelia cultivars have been used in many areas for landscaping and indoors in a variety of creative ways, but scientific reports of their pollination and hybridization are presently limited. Cross-combinations of Neoregelia cultivars were created to define conditions for pollination timing and to evaluate cross-compatibility. Neoregelia cultivars have short-lived flowers. Hybrid seeds were obtained only when cross-pollination was performed before $1200 \mathrm{HR}$. Results of 19 cross-combinations including six reciprocal crosses revealed that hybrid seeds were obtained in the female parents with a 1.9- to 2.0cm style length, but not in those with a $2.6-$ to $3.0-\mathrm{cm}$ style length. The pollen tube penetrated the ovule as early as 1 day after pollination in the compatible cross, whereas swollen pollen tubes were observed at half and two-thirds of the style in the incompatible cross. Removal of $50 \%$ of the style length of the female parents could overcome the fertilization barrier for those incompatible crosses and hybrid seeds could be successfully obtained.
\end{abstract}

Bromeliads have been widely used for potted flowers or landscape decoration for decades, and they are currently considered among the most valuable ornamental plants (Negrelle et al., 2012). Interspecific and intergeneric hybridizations have been made to develop new cultivars in several bromeliad genera, including Aechmea, Guzmania, Neoregelia, Tillandsia, and Vriesea (Parton et al., 2001; Smith, 1983; Vervaeke et al., 2001). Neoregelia cultivars have been popular because of their attractive multicolored foliage, even when the plants are not flowering. Therefore, they have been used in many areas for landscaping and indoor decorations. However, the cultivars that are of interest are hybrids.

Information regarding pollination timing is crucial for successful hybridization because some bromeliads have short-lived flowers and anthesis occurs at a particular time of the day (Foster, 1996; Souza et al., 2016). Foster (1958) stated that most Neoregelia flowers open and last only a few hours. Parton et al. (2001) showed that stigma receptivity was high at anthesis and then became significantly lower in Aechmea. Souza et al. (2016) showed higher stigma receptivity at anthesis for Aechmea, Alcantarea, Ananas, and Vriesea, with the highest

Received for publication 21 Aug. 2020. Accepted for publication 1 Oct. 2020.

Published online 30 October 2020.

This paper is a portion of a dissertation submitted by Chyun-Chien Liang.

D.M.Y. is the corresponding author. E-mail: dmyeh@ntu.edu.tw.

This is an open access article distributed under the CC BY-NC-ND license (https://creativecommons. org/licenses/by-nc-nd/4.0/). combinations.

*Significant at $P<0.05$ by $t$ test. attainment of intergeneric offspring (Vervaeke et al., 2002, 2003). The lack of seed formation in Vriesea and failure of seed germination in Aechmea occur despite fertilization, thus characterizing postfertilization barriers (Parton et al., 2001). Little information is available regarding the fertilization barriers of crossing Neoregelia species and/or cultivars.

The objectives of the present study were to 1) define the conditions for pollination timing, and 2) to observe whether the parental style length can affect seed formation when Neoregelia cultivars are crossed, and if so, if the cut style technique can overcome the fertilization barrier.

\section{Materials and Methods}

Plant materials and culture. Suckers of Neoregelia cultivars with six to eight leaves were removed from the stock plants after flowering and planted in plastic containers containing $1.2 \mathrm{~L}$ of coconut husk chips commonly used for the commercial production of bromeliads. Plants were grown in a glasshouse with an average noontime light intensity of 400 to $900 \mu \mathrm{mol} \cdot \mathrm{m}^{-2} \cdot \mathrm{s}^{-1}$ and temperature of 25 to $35^{\circ} \mathrm{C}$. Plants were fertilized monthly with water-soluble $20 \mathrm{~N}$ 8.7P-16.6K (20-20-20 General Purpose; JR Peters, Allentown, PA) at $1 \mathrm{~g} \cdot \mathrm{L}^{-1}$.

The corolla and anthers were removed in the female parent before the corolla lobes unfolded. Fresh pollen was always collected at anthesis and used immediately for crosspollination from March to May, when natural flowering occurred, between years 2008 and 2018. Three to four months after pollination, the seeds were collected, counted, and sown in 9-cm-diameter plastic pots containing coconut husk chips at 25 to $30{ }^{\circ} \mathrm{C}$ and $90 \%$ to

Table 1. Effects of pollination time on seed number per fruit and seed germination of Neoregelia cross-

\begin{tabular}{|c|c|c|c|}
\hline Crosses (cross no.) & Pollination time $\mathrm{z}^{\mathrm{z}}$ & Seed number per fruit & Seed germination (\%) \\
\hline Gold Fever $\times$ Pink & $0700-0950 \mathrm{HR}$ & $306.7 \mathrm{a}^{\mathrm{y}}$ & $\begin{array}{c}10.1 \\
\end{array}$ \\
\hline \multirow[t]{3}{*}{ Sensation (1) } & $1000-1250 \mathrm{HR}$ & $155.0 \mathrm{~b}$ & 60.7 \\
\hline & $1300-1550 \mathrm{HR}$ & $0 \mathrm{c}$ & - \\
\hline & $1600-1800 \mathrm{HR}$ & $0 \mathrm{c}$ & - \\
\hline \multirow[t]{2}{*}{ Gold Fever $\times$ Topaz (2) } & 0700-0950 HR & 291 & 82.4 \\
\hline & $1300-1550 \mathrm{HR}$ & ${ }^{0}$ & - \\
\hline Gold Fever $\times$ Perfecta & $0700-0950 \mathrm{HR}$ & 368 & 64.9 \\
\hline Tricolor (3) & $1300-1550 \mathrm{HR}$ & ${ }_{*}^{0}$ & - \\
\hline \multirow[t]{2}{*}{ Gold Fever $\times$ Puerto Rico (4) } & 0700-0950 HR & 160 & 83.0 \\
\hline & $1300-1550 \mathrm{HR}$ & ${ }_{*}^{0}$ & - \\
\hline Little Rose $\times$ Deroose's & 0700-0950 HR & 56 & 19.6 \\
\hline Medusa (5) & $1300-1550 \mathrm{HR}$ & $\begin{array}{l}0 \\
*\end{array}$ & - \\
\hline \multirow[t]{2}{*}{ Little Rose $\times$ Gespacho (6) } & 0700-0950 HR & 162 & 22.8 \\
\hline & $1300-1550 \mathrm{HR}$ & ${ }^{0}$ & - \\
\hline \multirow[t]{2}{*}{ Little Rose $\times$ Topaz (7) } & 0700-0950 HR & 214 & 22.4 \\
\hline & 1300-1550 HR & ${ }_{*}^{0}$ & - \\
\hline
\end{tabular}

$\overline{{ }^{z} \text { Corolla lobes unfolded at 0700-0950 HR, flowers were at anthesis at 1000-1250 HR, corolla lobes and }}$ stigma curling occurred at 1300-1550 HR, and flowers wilted at 1600-1800 $\mathrm{HR}$.

${ }^{\mathrm{y}}$ Mean separation within column by least significant difference at $P<0.05$ level. 
$100 \%$ relative humidity in a greenhouse. Seedling numbers and germination percentages were recorded at 2 weeks after sowing.

The origins of cultivars used in this study are as follows. 'Deroose's Medusa' is a spineless offspring selected from N. carolinae 'Meyendorffii'. 'Perfecta Tricolor' is a striped offspring selected from $N$. carolinae 'Marechalii'. 'Skotak's Orange Crush' is a hybrid derived from $N$. carolinae with an unknown male parent. 'Charm' is a hybrid derived from crossing $N$. marmorata and $N$. chlorosticta. 'Gespacho' is a hybrid derived from crossing $N$. chlorosticta and $N$. 'Fireball'. 'Gold Fever' is a hybrid derived from crossing $N$. 'Cinnabar' with an unknown male parent. 'Little Rose' is a hybrid derived from crossing $N$. chlorosticta with an unknown male parent. Both 'Pink Sensation' and 'Puerto Rico' are hybrids derived from crossing $N$. carolinae with unknown male parents. 'Topaz' is a hybrid derived from crossing $N$. 'Orange Delight' and $N$. olens. 'Orange Delight' is a hybrid derived from $N$. carolinae.

Expt. 1: Pollination timing. Fresh pollen of 'Pink Sensation' was carefully transferred to the stigma of 'Gold Fever' using forceps. Pollination was performed on sunny days at 0700-0950 HR (corolla lobes unfolded), 1000-1250 HR (flowers at anthesis), 1300$1550 \mathrm{HR}$ (corolla lobes curling inwards, stigma curling), and 1600-1800 HR (flowers wilted). More cross-pollination was performed at $0700-0950 \mathrm{HR}$ and $1300-1550 \mathrm{HR}$. The combinations included 'Gold Fever' as the female parent crossed with 'Topaz', 'Perfecta Tricolor', and 'Puerto Rico', and 'Little Rose' as the female parent crossed with 'Deroose's Medusa', 'Gespacho', and 'Topaz'. Each pollination timing consisted of three replicates. Seed number per fruit, expressed as an average of the replicates, was counted. Seed germination was recorded 2 weeks after being sown in a glasshouse at 25 to $30{ }^{\circ} \mathrm{C}$ under light intensity conditions of 400 to $900 \mu \mathrm{mol} \cdot \mathrm{m}^{-2} \cdot \mathrm{s}^{-1}$. A comparison between different pollination timing was performed using the least significant difference or $t$ test using CoStat 6.4 (CoHort Software, Monterey, CA).

Expt. 2: Cross-combinations between cultivars with different style lengths. Thirteen cross-combinations were made, including cultivars Perfecta Tricolor, Deroose's Medusa, Meyendorffii, and Skotak's Orange Crush with a long style length $(2.6-3.0 \mathrm{~cm})$ and cultivars Gold Fever, Gespacho, and Charm with a short style length (1.9-2.0 $\mathrm{cm})$. Thirty styles were measured from each cultivar to determine the average style length. An additional six reciprocal crosses were designed to determine whether the style length of the female parent could affect seed production. These include crosses between 'Gespacho' and 'Deroose's Medusa', 'Gold Fever' and 'Deroose's Medusa', and 'Gold Fever' and 'Perfecta Tricolor'. Each combination consisted of three to five replicates. Seed number per fruit, expressed as an average of the replicates, was counted.
In vivo pollen tube growth was observed following the methods described by Kho and Baër (1965) at $5 \mathrm{~d}$ after pollination in 'Skotak's Orange Crush' $\times$ 'Gespacho' and at $1 \mathrm{~d}$ after pollination in 'Gespacho' $\times$ 'Deroose's Medusa'. Samples of pollinated gynoecium were taken, fixed with $75 \%$ ethanol, and stored at $4{ }^{\circ} \mathrm{C}$. Then, samples were rinsed thoroughly with distilled water and softened with $1 \mathrm{~N}$ sodium hydroxide for 30 min at $65^{\circ} \mathrm{C}$ until semi-transparent. After being rinsed with distilled water, samples were stained with $0.025 \mathrm{M}$ aniline blue (Waldeck, Münster, Germany) solution (in $1 \mathrm{M}$ tripotassium phosphate) for $1 \mathrm{~h}$. Samples were observed with a microscope (Nikon

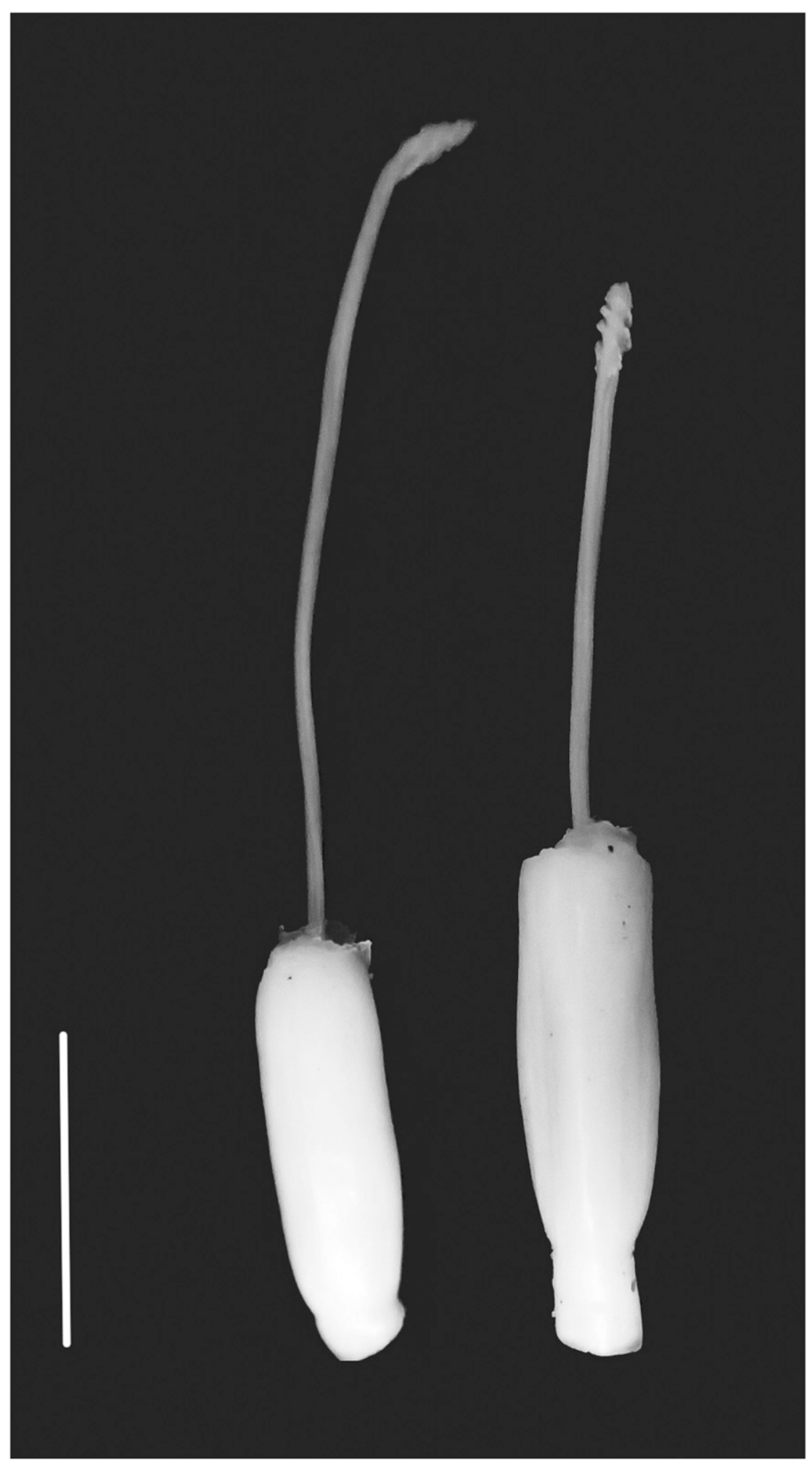

Fig. 1. Pistil of Neoregelia 'Meyendorffii' with a long style (left) and pistil of 'Gold Fever' with a short style (right). $\mathrm{Bar}=1 \mathrm{~cm}$. 
Eclipse E600; Nikon, Tokyo, Japan) equipped with a fluorescent lamp (450-490 nm) and a charge-coupled device digital camera (Optronics Microfire True Color Firewire Digital CCD; Meyer Instrument, Houston, TX). Each sample consisted of three to five replicates, and each replicate consisted of one gynoecium.

Expt. 3: Cut-style pollination. To overcome possible pollination barriers, we performed cut-style pollination following the methods described by Vervaeke et al. (2002, 2003). The upper $50 \%$ of the style length of the female parents was cut and removed with sharp scissors. Cross-combination included 'Perfecta Tricolor' $\times$ 'Gold Fever', 'Skotak's Orange Crush' $\times$ 'Gold Fever', and 'Meyendorffii' $\times$ 'Gold Fever'. Each combination consisted of three to five replicates. Seed number per fruit, expressed as an average of the replicates, was counted. A comparison of seed number was performed between intact styles (control) and styles with $50 \%$ of the length removed by using the $t$ test (CoStat 6.4; CoHort Software, Monterey, CA).

\section{Results and Discussion}

Expt. 1: Pollination timing. Emasculated flowers of 'Gold Fever' were cross-pollinated with 'Pink Sensation' from 0700 to $1800 \mathrm{HR}$. Results showed that more seeds but lower germination percentages were observed when pollinated between 0700 and $0950 \mathrm{HR}$ compared to between 1000 and $1250 \mathrm{HR}$ (Table 1). Pollination after 1300 HR resulted in no seed production (cross 1). Results from another six crosses (crosses 2-7) revealed that seeds were obtained when pollinated between 0700 and $0950 \mathrm{HR}$ as compared with no seed production when pollinated between 1300 and $1550 \mathrm{HR}$.

Our results indicate that successful pollination timing is rather short and that pollination should be performed before $1200 \mathrm{HR}$ for Neoregelia hybridization (Table 1). The flowers of some bromeliad species have a rather short opening and receptivity timeframe (Foster, 1958; Souza et al., 2016). Our previous unpublished investigations showed that Neoregelia pollen sampled $1 \mathrm{~d}$ after anthesis had a $20 \%$ to $70 \%$ germination rate when cultured in BK medium (Brewbaker and Kwack, 1963) containing 10\% sucrose. It was probable that no seed set would result from a short receptivity time; instead, pollen inviability resulted when cross-pollination was performed after $1200 \mathrm{HR}$.

Expt. 2: Cross-combinations between cultivars with different style lengths. Neoregelia have a dry stigma with multiseriate papillae, and cultivars differ in their style length (Heslop-Harrison and Shivanna, 1977) (Fig. 1; Table 2). Crosses between cultivars resulted in no seed production from female parents, with the style length ranging from 2.6 to $3.0 \mathrm{~cm}$ (crosses $8-14$ ). In contrast, 75 to 542 seeds per fruit were obtained from female parents with 1.9 - to $2.0-\mathrm{cm}$ style lengths (crosses 15-20). Parton et al. (2001) observed that differences in the style length of the female and male parents can influence seed production for other Bromelieaceae. Our results suggest that seed production appeared to be related to the style length of female parents for Neoregelia hybridization.

Reciprocal crosses were made to determine whether the maternal style length could affect seed production (Table 3). Results

showed that seeds were obtained only in female parents with a $1.9-\mathrm{cm}$ style length, whereas no seed production occurred in female parents with $2.6-$ to $2.8-\mathrm{cm}$ style length (crosses 21-26). Vervaeke et al. (2001) also reported unilateral congruity between Aechmea due to differences in style length.

At $5 \mathrm{~d}$ after pollination, swollen pollen tubes were observed in half to two-thirds of

Table 2. Seed number obtained from Neoregelia cross-combinations between cultivars with different style lengths.

\begin{tabular}{llcccc}
\hline & & & \multicolumn{2}{c}{ Style length (cm) } & \multirow{2}{*}{$\begin{array}{c}\text { Seed } \\
\text { number }\end{array}$} \\
\cline { 5 - 6 } Female parent & \multicolumn{1}{c}{ Male parent } & Cross no. & Female & Male & 0 \\
Perfecta Tricolor & Skotak's Orange & 8 & 2.8 & 2.7 & \\
Deroose's Medusa & Crush & & & & 0 \\
Meyendorffii & Perfecta Tricolor & 9 & 2.6 & 2.8 & 0 \\
Meyendorffii & Gold Fever & 10 & 3.0 & 1.9 & 0 \\
Skotak's Orange Crush & Gespacho & 11 & 3.0 & 1.9 & 0 \\
Skotak's Orange Crush & Geyendorffii & 12 & 2.7 & 3.0 & 0 \\
Skotak's Orange Crush & Gespacho & 13 & 2.7 & 1.9 & 0 \\
Gold Fever & Gespacho & 14 & 2.7 & 1.9 & 233.2 \\
Gold Fever & Charm & 15 & 1.9 & 1.9 & 187.0 \\
Gespacho & Gold Fever & 16 & 1.9 & 2.0 & 203.0 \\
Charm & Deroose's Medusa & 17 & 1.9 & 1.9 & 442.0 \\
Charm & Meyendorffii & 19 & 2.0 & 2.6 & 542.0 \\
Charm & Gespacho & 20 & 2.0 & 3.0 & 493.0 \\
\hline
\end{tabular}

Table 3. Seed number obtained from reciprocal crosses between Neoregelia cultivars with different style lengths.

\begin{tabular}{|c|c|c|c|c|}
\hline \multirow[b]{2}{*}{ Cross-combination } & \multirow[b]{2}{*}{ Cross no. } & \multicolumn{2}{|c|}{ Style length $(\mathrm{cm})$} & \multirow[b]{2}{*}{ Seed number } \\
\hline & & Female & Male & \\
\hline$\overline{\text { Gespacho } \times \text { Deroose's Medusa }}$ & 21 & 1.9 & 2.6 & 89.5 \\
\hline Deroose's Medusa $\times$ Gespacho & 22 & 2.6 & 1.9 & $\begin{array}{l}0 \\
*\end{array}$ \\
\hline Gold Fever $\times$ Deroose's Medusa & 23 & 1.9 & 2.6 & 93.0 \\
\hline Deroose's Medusa $\times$ Gold Fever & 24 & 2.6 & 1.9 & $\begin{array}{l}0 \\
*\end{array}$ \\
\hline Gold Fever $\times$ Perfecta Tricolor & 25 & 1.9 & 2.8 & 368.0 \\
\hline Perfecta Tricolor $\times$ Gold Fever & 26 & 2.8 & 1.9 & $\begin{array}{l}0 \\
*\end{array}$ \\
\hline
\end{tabular}

*Significant at $P<0.05$ by $t$ test.

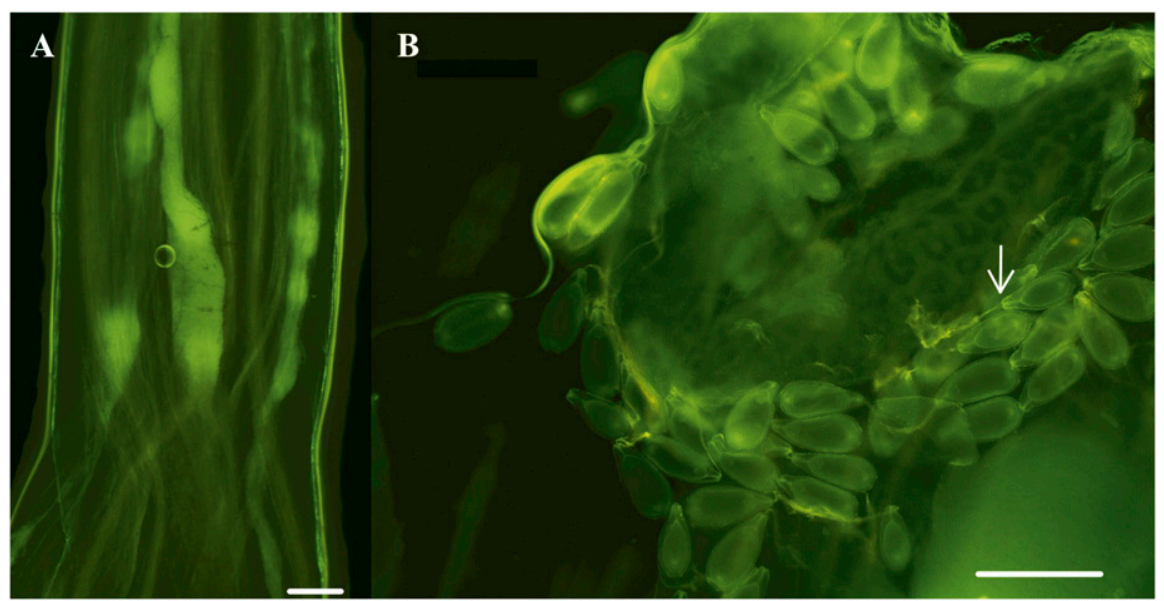

Fig. 2. The abnormal swollen pollen tubes in half and two-thirds of the style in Neoregelia 'Skotak's Orange Crush' crossed with 'Gespacho' $5 \mathrm{~d}$ after pollination (A). Pollen tubes penetrated the micropyle in 'Gespacho' crossed with 'Deroose's Medusa' $1 \mathrm{~d}$ after pollination (B). Arrow indicates pollen tubes. Bar $=200 \mu \mathrm{m}$. 
Table 4. Effect of the removal of $50 \%$ of the style length of the female parent on seed number of three Neoregelia cross-combinations.

\begin{tabular}{|c|c|c|}
\hline Crosses (cross no.) & Style $^{z}$ & Seed number \\
\hline \multirow[t]{2}{*}{ Perfecta Tricolor $\times$ Gold Fever (27) } & - & 0.0 \\
\hline & + & $\begin{array}{c}227.3 \\
*\end{array}$ \\
\hline \multirow[t]{2}{*}{ Skotak's Orange Crush $\times$ Gold Fever (28) } & - & 0.0 \\
\hline & + & $\begin{array}{c}125.0 \\
*\end{array}$ \\
\hline \multirow[t]{2}{*}{ Meyendorffii $\times$ Gold Fever $(29)$} & - & 0.0 \\
\hline & + & $\begin{array}{c}25.0 \\
*\end{array}$ \\
\hline
\end{tabular}

${ }^{\mathrm{z}}$ Intact style (-) or removal of $50 \%$ of the style length $(+)$.

*Significant at $P<0.05$ level by $t$ test.

the style in the 'Skotak's Orange Crush' $x$ 'Gespacho' cross (Fig. 2A), which may explain why this combination did not produce any seeds (cross 14) (Table 2). A swollen pollen tube and callose deposition at the tube tip have been documented in intraspecific, interspecific, and intergeneric crosses, even when the cross seemed to be congruent (Parton et al., 2001; Souza et al., 2017). Deposition of the callose influenced the maintenance of turgor pressure and osmotic balance in the pollen tube. Regular callose deposition can serve as a mechanical barrier preventing plasma at the apex from flowing backward or preventing the pollen tubes from shrinking (Souza et al., 2017). However, there is a close relationship between incompatibility and callose deposition on pollen tubes. For example, an abnormally increased deposition of callose resulted in incompatible swollen pollen tubes bursting within the style in Petunia ×hybrida (Ünal et al., 2013). We suggest that the incompatibility in the 'Skotak's Orange Crush' $\times$ 'Gespacho' cross was due to the rejection reaction of the pollen tube and style. In contrast, pollen tubes had penetrated the ovule as early as $1 \mathrm{~d}$ after pollination in 'Gespacho' $\times$ 'Deroose's Medusa' (Fig. 2B), which led to seed production (cross 21) (Table 3).

Expt. 3: Cut-style pollination. Removal of $50 \%$ of the style length of the female parents resulted in seed production. No seed was obtained from the female parents with an intact long style (Table 4). These results are consistent with previous observations that the style length of the female parents could affect successful cross-pollination (Tables 2 and 3 ).

Several techniques that can be used to overcome reproductive barriers in Bromelieaceae were described by Vervaeke et al. (2002), such as cut-style pollination, placental graftedstyle pollination, and placental pollination. The present study showed that cut-style pollination could bypass the pollen-style rejection reaction in the incompatible crosses in Neoregelia and obtain hybrid seeds. The cutstyle techniques have been used successfully to develop intergeneric hybrids of Aechmea (Vervaeke et al., 2002, 2003).

\section{Conclusions}

Neoregelia cultivars have short-lived flowers; therefore, cross-pollination should be performed before $1200 \mathrm{HR}$. Crosses between Neoregelia cultivars may have prefertilization barriers confined within the style, as reported previously for other Bromelieaceae (Vervaeke et al., 2001, 2002). We suggest using female parents with a short style for successful crosspollination because unilateral incongruity appeared to be related to the female style length. Removal of $50 \%$ of the style length of female parents could overcome the prefertilization barrier and obtain hybrid seeds.

\section{Literature Cited}

Brewbaker, J.L. and B.H. Kwack. 1963. The essential role of calcium ion on pollen germination and pollen tube growth. Amer. J. Bot. 50:859-865, doi: 10.2307/2439772.
Foster, M.B. 1958. Neoregelia-Nidularium? A perennial question. Bromeliad Soc. Bull. 8:67-68.

Foster, M.B. 1996. Pollination and hybridization. Flor. Council Bromeliad Soc. Nwsl. $16: 3-5,19$

Heslop-Harrison, Y. and K.R. Shivanna. 1977. The receptive surface of the angiosperm stigma. Ann. Bot. 41:1233-1258, doi: 10.1093/oxfordjournals.aob.a085414.

Kho, Y.O. and J. Baër. 1965. Observing pollen tubes by means of fluorescence. Euphytica 17:298-302, doi: 10.1007/BF00021224.

Negrelle, R.R.B., D. Mitchell, and A. Anacleto. 2012. Bromeliad ornamental species: Conservation issues and challenges related to commercialization. Acta Sci. Biol. Sci. 34:91-100, doi: 10.4025/actascibiolsci.v34i1.7314.

Parton, E., I. Vervaeke, R. Deroose, and M.P. De Proft. 2001. Interspecific and intergeneric fertilization barriers in Bromeliaceae. Acta Hort. 552:43-53, doi: 10.17660/actahortic. 2001.552.4

Smith, L.B. 1983. Bigeneric hybrids - A listing. J. Bromeliad Soc. 33:69-75.

Souza, E.H., S.M. Carmello-Guerreiro, F.V.D. Souza, M.L. Rossi, and A.P. Martinelli. 2016. Stigma structure and receptivity in Bromeliaceae. Scientia Hort. 203:118-125, doi: 10.1016/ j.scienta.2016.03.022.

Souza, E.H., L.M. Versieux, F.V.D Souza, M.L. Rossi, M.A.P. de C. Costa, and A.P. Martinelli. 2017. Interspecific and intergeneric hybridization in Bromeliaceae and their relationships to breeding systems. Scientia Hort. 223:53-61, doi: $10.1016 /$ j.scienta.2017.04.027.

Ünal, M., F. Vardar, and Ö. Aytürk. 2013. Callose in plant sexual reproduction. In: M. Silva-Opps (ed.). Current progress in biological research. IntechOpen. 1 Oct. 2010. <https://www.intechopen.com/books/current-progress-in-biologicalresearch/callose-in-plant-sexual-reproduction>. https://doi.org/10.5772/53001.

Vervaeke, I., E. Parton, L. Maene, R. Deroose, and M.P. De Proft. 2001. Prefertilization barriers between different Bromeliaceae. Euphytica 118:91-97, doi: 10.1023/A:1004016709231.

Vervaeke, I., E. Parton, L. Maene, R. Deroose, and M.P. De Proft. 2002. Pollen tube growth and fertilization after different in vitro pollination techniques of Aechmea fasciata. Euphytica 124:75-83, doi: 10.1023/A:1015650120583.

Vervaeke, I., R. Deroose, and M.P. De Proft. 2003. Interspecific and intergeneric hybridization in Bromeliaceae. Acta Hort. 624:77-83, doi: 10. 17660/ActaHortic.2003.624.10 